\title{
En memoria de Vicki Cassman, Ph.D.
}

\author{
Julia Córdova-González Ph.D. ${ }^{1}$
}

Vicki, la hacedora de caminos de perfección, se nos ha adelantado en la ruta hacia otras esferas del mundo sideral. Por las demandas de una actividad profesional intensa, ya hacía bastante tiempo que no tenía la oportunidad de conversar y conocer sus proyectos de primera fuente, sin embargo, nunca estuve demasiado lejos de su producción académica, debido a lo significativo de su aporte para nuestro entorno. La recuerdo muy vívidamente desde su llegada a nuestro Departamento de Antropología y Museo en Azapa en 1983, puesto que marcó un hito de importancia en el perfeccionamiento de nuestras especialidades. Ese año, Vicki y Michelle Austin iniciaban en nuestro Museo su internado, como parte de los requisitos del Master in Art Conservation ofrecido por el Instituto Winterthur, Department of Art Conservation Universidad de Delaware, USA.

Puesto que en Chile no existían escuelas de museología, nuestra aproximación a esta disciplina era muy bien intencionada pero del todo empírica. Partiendo de nuestros conocimientos profesionales, íbamos desarrollando nuevos procedimientos sobre la base de literatura, cursos, encuentro entre pares y praxis, pero llegó Vicki, permitiéndonos conocer otros enfoques, métodos científicos y lugares donde podríamos adquirirlos. Se convirtió en la embajadora del Instituto Winterthur, cuya misión es el estudio interdisciplinario para la conservación del patrimonio cultural, en consideración a que este forma parte integral de la experiencia humana, particularmente en el ámbito de la educación y el desarrollo ${ }^{1}$.

En la búsqueda de posibilidades de perfeccionamiento para nuestro Museo San Miguel de Azapa -Universidad de Tarapacá- Vicki gestionó, junto con Liliana Ulloa, conservadora de textiles arqueológicos del Departamento, un convenio de intercambio profesional y aprendizaje, apoyado por nuestra Universidad y la Fulbright Commission. Así Mariela Santos se perfeccionó en conservación de objetos y Liliana avanzó su conocimiento en conservación de textiles antiguos ${ }^{2}$, ambas desarrollaron sus actividades en Winterthur (Wilmington); yo, en cambio, tuve la oportunidad de participar en el área de Museum Studies (Educación, Manejo de colecciones, Exposición de objetos culturales y Administración) en la Old College Gallery de la Universidad de Delaware en
Newark. Fue un gran paso hacia adelante para las tres. Personalmente, creo que la experiencia académica que obtuve en ese entorno se la debo a la generosidad de Vicki, a su afán por abrir puertas en el campo que la apasionaba. También debe haber participado en la decisión de que mi trabajo de investigación y documentación de cincuenta piezas de arte precolombino de la Colección Lickle de esa galería universitaria, tomara la forma de una exposición en el Museo de Winterthur, y se publicara en el catálogo de esa exposición.

Su alma de maestra se apreciaba en todo momento. Llegó a Arica para conocer nuestro material, pero a través de seminarios que nos impartía y de conversaciones profundas nos iba orientando a como ver más allá de una práctica dedicada. Su voz dulce y reposada, su mirada limpia y sincera, sus gestos amistosos nos acercaban al conocimiento que iba generando y que compartía con generosidad. Al darme la noticia de su partida, Liliana me dijo, falleció nuestra Vicki; muy cierto, siempre la sentimos nuestra, no obstante su vinculación académica con las Universidades de Delaware, de Nevada, y con los numerosos museos y centros de investigación que solicitaron sus enseñanzas, las que entregaba con dedicación notable.

Ella, como arqueóloga y conservadora de bienes culturales patrimoniales, comprendía muy bien que un museo arqueológico contiene la historia del ser humano. El museo, como entidad viviente, es fuente inagotable de mensajes que necesitan ser abordados, a través de la ciencia, en su abanico de enfoques y especialidades. Puesto que el patrimonio cultural común es la base del sustento vital para la humanidad, los hallazgos en este campo -a los que la investigación ha dado forma- requieren ser comunicados, a fin de estimular la construcción de un conocimiento que nos enriquece como sociedad. Esto se hacía realidad en Vicki, una investigadora y docente nata a quien tuvimos el privilegio de conocer.

Imagino que ahora estará tejiendo o reparando los tramos de los caminos ya transitados, para que sus amigos-discípulos alcancemos también, en un futuro cualquiera, esos espacios poblados de estrellas donde se encuentra. Su recuerdo nos ilumina y nos estimula en nuestro empeño por hacer las cosas mejor.

\section{Notas}

\footnotetext{
${ }^{1}$ Educación de Museo Universidad de Tarapacá San Miguel de Azapa, Arica, Chile.
} 